\title{
Full-Thickness Isolated Small Intestine Injury Due to Blunt Trauma
}

\author{
Zülfü Arıkanoğlu, Fatih Taşkesen, Mesut Gül, İbrahim Aliosmanoğlu, Akın Önder, Murat Kapan \\ Department of General Surgery, Dicle University Faculty of Medicine, Diyarbakır, Turkey
}

\begin{abstract}
Isolated small intestine injury because of blunt trauma is a rarely encountered situation. Because it is difficult to diagnose, this injury can be associated with a prolonged clinical course and delay in treatment. In this article, we present an isolated full-thickness ileal trauma associated with a motor vehicle traffic accident. A 35-year-old male patient was kept under observation at another medical center following the motor vehicle traffic accident and was discharged early because no pathology was detected. He was later referred to our hospital's emergency clinic with complaints of abdominal pain and vomiting after approximately 12 hours. The patient with acute abdomen was assessed by physical examination, laboratory tests, and imaging and was taken into surgery under emergency conditions. A full-thickness isolated ileal perforation and approximately $300 \mathrm{~mm}^{3}$ of intestinal contents were detected by laparotomy. Resection of necrotic tissues and end-to-end anastomosis was performed. During the post-operative period, he was discharged without complications. Even in situations in which a thorough investigation and examination are performed, considering that there might be an isolated case of small intestine trauma, it is very important to extend the monitoring, imaging, and observation periods of patients with blunt trauma with repeated physical examinations.

(Eurasian JEmerg Med 2015; 14: 204-6)
\end{abstract}

Keywords: Blunt trauma, isolated small intestine perforation, treatment

\section{Introduction}

Generally, hollow organ injuries occur after penetrating abdominal trauma and exhibit clinical symptoms at early period. Because solid organ injuries have a higher priority in the cases of blunt abdominal trauma, hollow organ injuries are not commonly seen. Although small bowel is the third most commonly injured organ after thoracic and heart injuries, in cases of blunt abdominal trauma, less than $1 \%$ of blunt trauma patients exhibit small bowel injury; only $0.3 \%$ of the patients demonstrate small bowel perforation. The most commonly injured organs in blunt traumas are the jejunum, ileum, and duodenum. The proximal jejunum and terminal ileum are the most commonly injured parts of these hollow organs. Isolated bowel injuries are very rare and often present with accompanying organ injuries (1-3).

Because the occurrence of clinical symptoms in small bowel injuries associated with blunt trauma may take time, the initial examinations appear to be normal. Imaging modalities may fail to establish a diagnosis. Such delays in diagnosis and treatment lead to increased morbidity and mortality $(1,4,5)$.
In this study, we present the case of a 35-year-old male patient with full-thickness isolated ileal perforation after a blunt trauma who was diagnosed and treated in a delayed fashion.

\section{Case Presentation}

The patient was kept under monitoring in another health center because he suffered from a traffic accident while being inside a vehicle and was discharged after no pathology was detected. Approximately $12 \mathrm{~h}$ after the accident, the patient visited our emergency unit with the complaints of abdominal pain and vomiting. Physical examination revealed signs of peritonitis. Complete blood count $(C B C)$ and biochemical profile yielded the following results: white blood cell (WBC), $13.8 \mathrm{k} / \mathrm{uL}$; hemoglobin (Hgb), $13 \mathrm{~g} / \mathrm{dL}$; hematocrit (Htc), 40.4\%; platelets (Plt), 219000 k/uL; urea, 80; creatinine, 1.4; glucose, $220 \mathrm{mg} / \mathrm{dL}$; aspartate aminotransferase (AST), $110 \mathrm{U} / \mathrm{L}$; and lactate dehydrogenase (LDH), $391 \mathrm{U} / \mathrm{L}$. The remaining parameters were within the normal range. Posteroanterior lung $\mathrm{X}$-ray and erect plain abdominal X-ray showed no abnormal sign. Contrast whole-abdomen tomography revealed free air and dif-

Correspondence to: Zülfü Arıkanoğlu e-mail: zulfuarikanoglu@gmail.com 


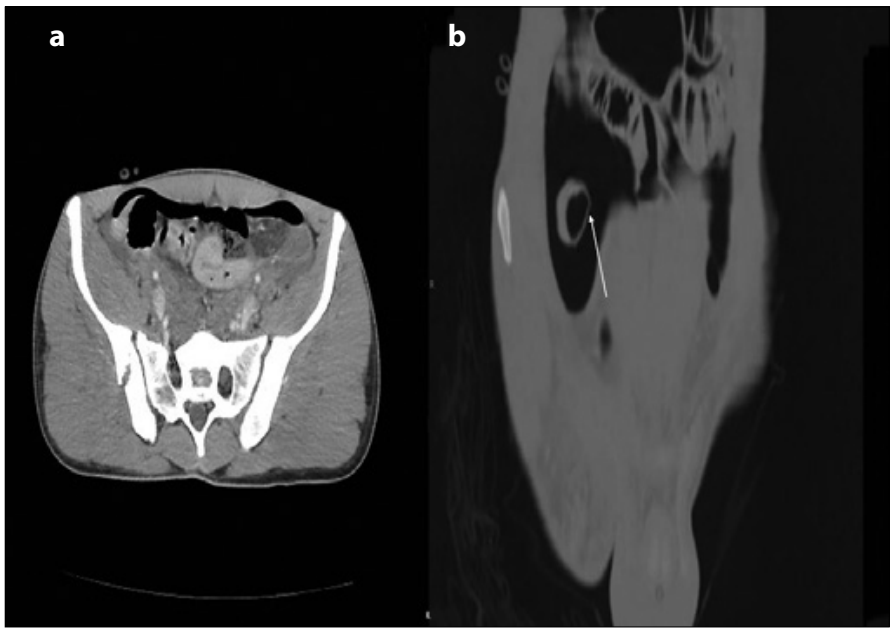

Figures 1. a, b. Post-contrast CT scan (a: axial, b: coronal); loss of integrity (arrow) and surrounding free fluid in the terminal ileum

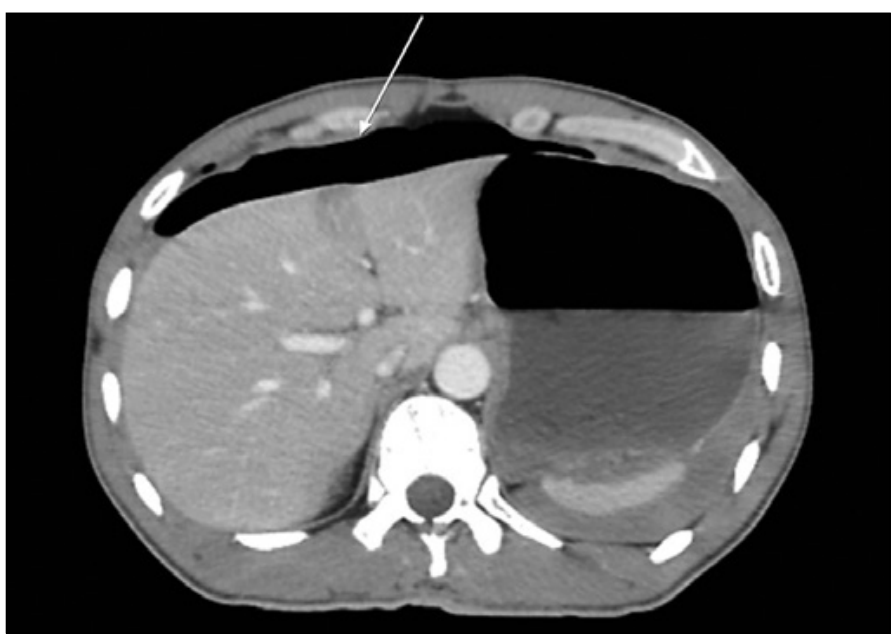

Figure 2. Axial post-contrast CT showing the presence of diffuse free air (arrow) anterior to the liver

fuse free fluid collections in the abdomen (Figure $1 \mathrm{a}, \mathrm{b}$, Figure 2). Signed informed written consent was obtained from the patient. The patient received emergency surgery. Laparotomy revealed a full-thickness isolated ileal perforation $180 \mathrm{~cm}$ distal to the Treitz ligament and $300 \mathrm{~mm}^{3}$ of bowel content in the abdomen. Necrotic tissues were resected, and end-to-end anastomosis was performed. The patient was discharged without complication after 8 days postoperatively.

\section{Discussion}

The most commonly injured organ in penetrating abdominal traumas is the small bowel; in blunt abdominal traumas, the most commonly injured organs are the liver and spleen. Although small bowel injury is the third most common type of injury after thoracic and heart injuries in blunt abdominal traumas, small bowel injury is seen in less than $1 \%$ of patients with blunt trauma. Among these patients, only $0.3 \%$ patients demonstrate small bowel perforation $(1-3,6)$. Traffic accidents are the cause in $60 \%-80 \%$ of small bowel injuries associated with blunt trauma. Seat belts worn by motor vehicle occupants is the most important factor leading to small bowel injury (7). The mechanism of small bowel injury in blunt trauma often involves vertebral compression because of trauma experienced by the abdominal wall, leading to increased pressure in the bowel lumen. In some cases, the injury occurs in response to rising tension between the sudden anterior movement of bowels and the fixed intestinal components such as the Treitz ligament, ileocecal angle, and mesentery root. The blunt injuries of the small bowel may present as intramural hematoma, contusion, laceration, or rupture $(2,8)$.

Small bowel injury associated with blunt abdominal trauma has a poorer prognosis than small bowel injury following a penetrating abdominal trauma. The main reason underlying this is the accompanying major extra-abdominal organ injury and delayed diagnosis (9). Clinical symptoms are typical when there is a full-thickness perforation in the small bowel.

However, physical examination and specific diagnostic modalities may yield negative results shortly after trauma. Subsequent to tertiary examinations, the development of peritoneal signs or presence of increased leukocyte, amylase, and alkaline phosphatase in the lavage fluid are of diagnostic value. In our case, the presence of positive peritoneal signs and findings indicative of free air and fluid in the contrast abdominal tomography both support the diagnosis. When the bowel injury is in the form of a hematoma or rupture or when there is a hematoma or rupture formation in the bowel mesentery, then physical examination does not reveal pathological signs. Because of the gradual development of necrosis, the signs may present themselves in a delayed fashion (6).

Ultrasonography (USG) and abdominal computed tomography (CT) have not been proven to be valuable in the early diagnosis of isolated small bowel injuries. As in our case, plain X-ray is often unreliable. Many patients present with no intraperitoneal free air. USG has been commonly employed in blunt abdominal traumas because it is portable, fast, noninvasive, and does not require contrast agent. However, because it depends on the capability of the operating physician, the accuracy rate increases only with experience (9). CT, the best diagnostic method, has a sensitivity and specificity of $92 \%$ and $94 \%$, respectively, in small bowel perforation. The differential diagnoses of small bowel perforation on CT scan are contrast agent extravasation and the presence of extraluminal free air. The findings that are not diagnostic but supportive for perforation are the presence of free fluid without any solid organ injury as well as thickening and dilatation in the small bowel wall $(5,7)$.

In the treatment, explorative laparotomy, drainage of the septic peritoneal fluid, and lavage are important. Moreover, prophylactic antibiotics are required. The method used for repairing the perforation depends on the localization of the injury and diameter of the defect. Primary repair of small defects as well as resection and primary anastomosis of large defects and ischemic segments can be performed without any complications even in delayed cases $(9,10)$.

\section{Conclusion}

Isolated small bowel injury following blunt abdominal trauma is a considerably rare case. Even when early tests and assessments yield negative results, it is important to repeat physical examinations and to continue the monitoring of patients. On performing abdominal USG and CT, the presence of intraperitoneal free fluid without solid organ injury supports the diagnosis of small bowel injury. 
Informed Consent: Written informed consent was obtained from the patient for publication of this case report and any accompanying images.

Peer-review: Externally peer-reviewed.

Conflict of Interest: No conflict of interest was declared by the authors.

Financial Disclosure: The authors declared that this study has received no financial support.

\section{References}

1. Coskun AK, Yarici M, Ulke E, Mentes O, Kozak O, Tufan T. Perforation of isolated jejunum after a blunt trauma: case report and review of the literature. Am J Emerg Med 2007; 25: 862.e1-4. [CrossRef]

2. Fraga GP, Silva FH, Almeida NA, Curi JC, Mantovani M. Blunt abdominal trauma with small bowel injury: are isolated lesions riskier than associated lesions? Acta Cir Bras 2008; 23: 192-7. [CrossRef]

3. Maharaj D, Perry A, Ramdass M, Naraynsingh V. Late small bowel obstruction after blunt abdominal trauma. Postgrad Med J 2003; 79: 57-8. [CrossRef]
4. Munshi IA, DiRocco JD, Khachi G. Isolated jejunal perforation after blunt thoracoabdominal trauma. J Emerg Med 2006; 30: 393-5. [CrossRef]

5. Saku M, Yoshimitsu K, Murakami J, Nakamura Y, Oguri S, Noguchi T, et al. Small bowel perforation resulting from blunt abdominal trauma: interval change of radiological characteristics. Radiat Med 2006; 24: 358-64. [CrossRef]

6. Analay H, Gökgöz MŞ, Yıldırır C, Turan M, Aker B. İnce bağırsak yaralanmaları. Ulusal Travma Dergisi 1997; 3: 288-90.

7. Kostantinidis C, Pitsinis V, Fragulidis G. Isolated jejunal perforation following blunt abdominal trauma. Ulus Travma Acil Cerrahi Derg 2010; 16: 87-9.

8. Dongo AE, Kesieme EB, Irabor DO, Ladipo JK. A review of posttraumatic bowel injuries in ibadan. ISRN Surg 2011; 478042. [CrossRef]

9. Sözüer EM, Bedirli A, Íkizceli İ, Yeşilkaya Y. Künt travmaya bağlı izole ince bağırsak yaralanmalarında cerrahi tedavi. Ulusal Travma Dergisi 1997; 3: 298-302.

10. Mukhopadhyay M. Intestinal Injury from Blunt Abdominal Trauma: A Study of 47 Cases. Oman Med J 2009; 24: 256-9. [CrossRef] 